einstein

Official Publication of the Instituto Israelita de Ensino e Pesquisa Albert Einstein

ISSN: 1679-4508 | e-ISSN: 2317-6385
LEARNING BY IMAGES

\section{COVID-19 pneumonia and target sign}

Pneumonia por COVID-19 e o sinal do alvo

Lucas de Pádua Gomes de Farias ${ }^{1}$, Daniel Giunchetti Strabelli', Gustavo Borges da Silva Teles ${ }^{1}$

1 UnitedHealth Group, São Paulo, SP, Brazil.

DOI: 10.31744/einstein_journal/2021AI6564
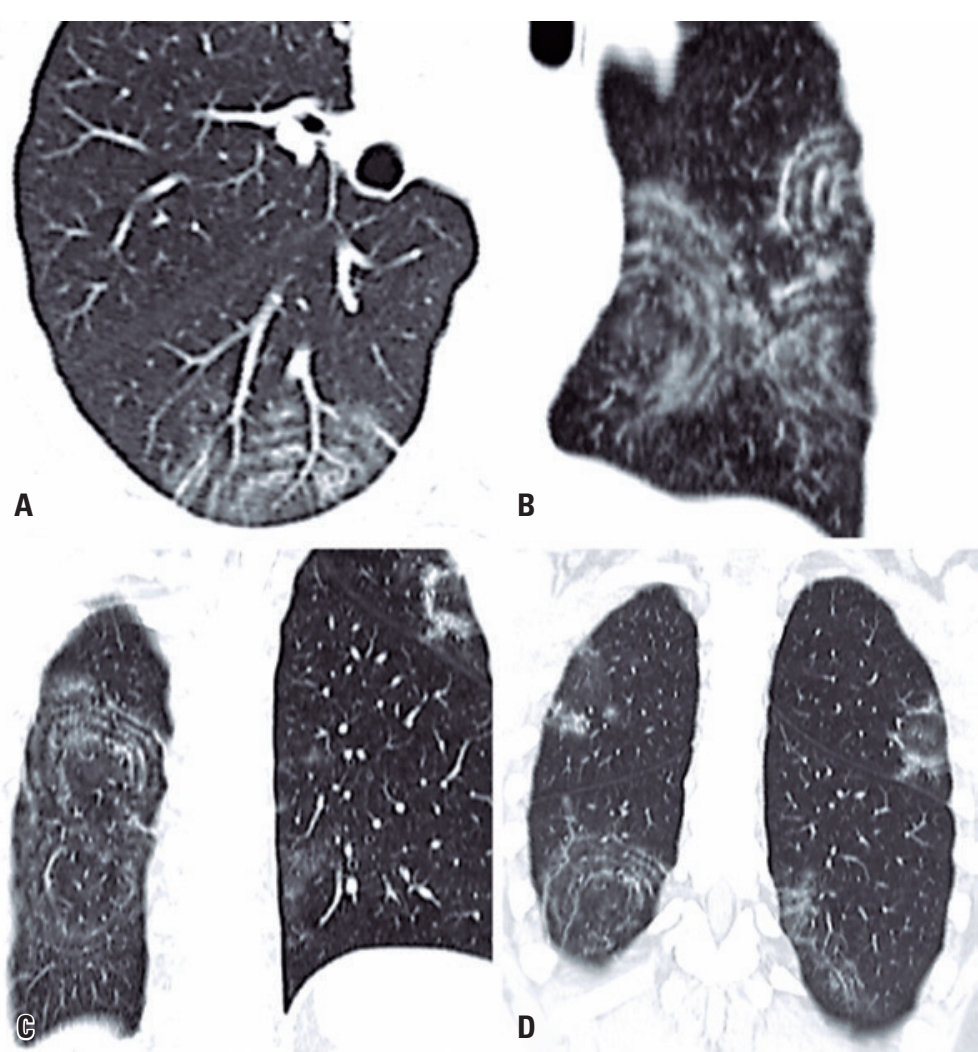

Figure 1. Chest computed tomography imaging (A) axial, (B) sagittal oblique, and ( $C$ and $D$ ) coronal oblique show the target sign characterized by multiple concentric ring-like opacities, with a central nodular peribronchovascular opacity, in a 49-year-old man with COVID-19 pneumonia. Note the reversed halo sign in the left upper lobe

A 49-year-old man came to our emergency department with a 2-day history of fever, cough, anosmia, ageusia and odynophagia. His past medical history included hypertension. At the time of this presentation, chest computed tomography revealed peripheral and bilateral ground-glass opacities, with some visible intralobular lines - typical findings of pneumonia caused by the severe acute respiratory syndrome coronavirus 2 (SARS-CoV-2). In addition, some findings revealed the target sign (Figure 1). The patient's supportive treatment was continued, and reverse-transcriptase polymerase chain reaction (RT-PCR) confirmed the infection by SARS-CoV-2. 
The target sign has been recently described and associated with organizing pneumonia and vascular features related to the viral infection. ${ }^{(1-3)}$ It is characterized by a nodular opacity in the center of a ring-like opacity, which can have ground-glass or consolidation attenuation, as well multiple concentric ring-like opacities. ${ }^{(4)}$ When only with one or two ringlike opacities, this sign is not specific to COVID-19, and the differential diagnosis includes conditions other than organizing pneumonia, such as metastasis and post-radiofrequency ablation zone. ${ }^{(5,6)}$ However, the manifestation with multiple concentric ring-like opacities (Figure 1) has only been reported so far in patients with COVID-19 pneumonia. ${ }^{(4)}$

We emphasize the importance of familiarizing radiologists with imaging findings of COVID-19 pneumonia to contribute to its diagnostic suspicion. The description of new radiological patterns, so far infrequent or little known, is of great value in the scenario of the SARS-CoV-2 pandemic, since the use of chest computed tomography has increased significantly in patients suspected to have COVID-19 pneumonia. It is noteworthy that further studies are still required to better assess the target sign and its accuracy in SARS-CoV-2 infection.

\section{AUTHORS' INFORMATION}

Farias LP: http://orcid.org/0000-0001-5195-9818

Strabelli DG: http://orcid.org/0000-0002-0526-5775

Teles GB: http://orcid.org/0000-0002-5405-5029

\section{REFERENCES}

1. Lang M, Som A, Carey D, Reid N, Mendoza DP, Flores EJ, et al. Pulmonary vascular manifestations of COVID-19 pneumonia. Radiol Cardiothorac Imaging. 2020;2(3):e200277.

2. Ackermann M, Verleden SE, Kuehnel M, Haverich $A$, Welte $T$, Laenger $F$, et al. Pulmonary vascular endothelialitis, thrombosis, and angiogenesis in Covid-19. N Engl J Med. 2020;383(2):120-8.

3. Pogatchnik BP, Swenson KE, Sharifi H, Bedi H, Berry GJ, Guo HH. Radiologypathology correlation demonstrating organizing pneumonia in a Patient Who Recovered from COVID-19. Am J Respir Crit Care Med. 2020;202(4):598-9.

4. Farias LP, Souza FH, Teles GB. The target sign and its variant in COVID-19 Pneumonia. Radiol Cardiothorac Imaging. 2020;2(4):e200435.

5. Marchiori E, Silva JA, Amorim VB, Zanetti G. Is the CT target sign specific to COVID-19 pneumonia? J Bras Pneumol. 2020;46(6):e20200541.

6. Abtin FG, Eradat J, Gutierrez AJ, Lee C, Fishbein MC, Suh RD. Radiofrequency ablation of lung tumors: imaging features of the postablation zone. Radiographics. 2012;32(4):947-69. Review. 